\title{
The importance of surgical education in the accuracy of implant placement during hip fracture fixation
}

\author{
Vinay Parmar · A. J. Shyam Kumar
}

Received: 28 June 2008/Accepted: 3 February 2009/Published online: 13 March 2009

(C) Springer-Verlag 2009

\begin{abstract}
Background Studies have found that tip apex distance (TAD) is the strongest independent predictor of lag screw cut-out following hip fracture fixation. The objective of this study was to understand the importance of introducing the concept of TAD to surgeons. The null hypothesis was that there were no differences between fractures fixed before awareness of TAD compared with fractures fixed after awareness of TAD.

Materials and Methods This study involved assessing 75 consecutive radiographs retrospectively (before introduction of "tip apex distance" to surgeons) and 83 consecutive radiographs prospectively (after introduction of "tip apex distance" to surgeons). Radiographs were measured using a radiograph digitizer and software.

Results Average TAD in radiographs measured retrospectively was $22.6 \mathrm{~mm}$ compared with $9.7 \mathrm{~mm}$ in radiographs analysed prospectively $(P \leq 0.001)$. The power of this study was $97 \%$.

Conclusion This study demonstrates that introducing the concept of "TAD" to surgeons, will improve the accuracy
\end{abstract}

This study was supervised by the late Professor Harper, Professor of Orthopaedic Surgery at the University of Leicester, who sadly died in 2008. Our thoughts are with him.

\section{Parmar}

University of Manchester, South Manchester University Hospital NHS Trust, Manchester, UK

\author{
A. J. S. Kumar \\ North Wales Rotation, North Wales, UK \\ V. Parmar $(\bowtie)$ \\ 192 Prince of Wales Lane, Birmingham B14 4LH, UK \\ e-mail: Vp0909@hotmail.com
}

of lag screw placement during fixation of an extracapsular fracture. The improvements in lag screw placement will undoubted reduce cut-out of the implant post-surgery.

Keywords Hip fracture - Education - Tip apex distance . Cut-out

\section{Introduction}

Cutting out of the lag screw from the femoral head is the most common cause of failure of fixation in an extracapsular fracture of the neck of the femur [1]. The concept of TAD has been introduced by Baumgaertner as the strongest predictor of cut-out of the lag screw of an implant within the femoral head [2]. "The tip-apex distance is defined as the sum of the distance, in millimetres, from the tip of the lag screw to the apex of the femoral head as measured on an anteroposterior radiograph and lateral radiograph, after correction has been made for magnification" [2]. TAD less than $25 \mathrm{~mm}$ is said to be desirable to prevent cut-out of the lag screw [2].

Pervez has also conducted a study involving 23 cases of cut-out compared with 77 cases of uneventful fracture healing [3]. TAD was, again, found to be the most significant difference between patients with cut-out (average $\mathrm{TAD}=38 \mathrm{~mm}$ ) against those without (average $\mathrm{TAD}=$ $24 \mathrm{~mm})(P=0.001)$.

Failure of fixation has been reported to have an incidence of between $5.3 \%$ and $16.8 \%$ and cut-out has been shown to be the commonest cause of fixation failure of an extracapsular fracture treated by a sliding hip screw [1]. $\mathrm{TAD}$ is therefore a predictor of fracture fixation failure.

Table 1 summarises the data from two important studies assessing the correlation between TAD and cut-out. 
Table 1 Summary of studies correlating TAD with cut-out

\begin{tabular}{lllll}
\hline Study author and year & $\begin{array}{l}\text { Average TAD in } \\
\text { cut-out group (mm) }\end{array}$ & $\begin{array}{l}\text { Number of cases } \\
\text { of cut-out }\end{array}$ & $\begin{array}{l}\text { Average TAD in control/ } \\
\text { non-cut-out group (mm) }\end{array}$ & $\begin{array}{l}\text { Number of cases in } \\
\text { control/non-cut-out group }\end{array}$ \\
\hline Pervez (2004) & 27 & 23 & 20 & 77 \\
Baumgaertner (1995) [2] & 38 & 16 & 24 & 182 \\
\hline
\end{tabular}

Shorter TAD is desirable for prevention of cut-out of the lag screw from the femoral head. This study aims to determine whether educating surgeons on the concept of $\mathrm{TAD}$, and its importance, has an effect on their accuracy of lag screw placement (TAD) and, therefore, the future the risk of cut-out.

The null hypothesis was that there were no differences between fractures fixed before awareness of TAD compared with fractures fixed after awareness of TAD.

\section{Materials and methods}

This study involved assessing 75 consecutive radiographs retrospectively and 83 consecutive radiographs prospectively of images of extra-capsular fractures fixed with either a cephalocondylic nail or sliding hip screw plate system.

Retrospective images were obtained by identifying entries in theatre lists, and notes were then obtained from the hospital records library. Each set of notes contained perioperative digital image intensifier radiographs, which were subsequently scanned (AP and lateral).

Following appointment of a hip fellow, the concept of tip apex disease in femoral fixation was identified, and the hip fellow and other surgical colleagues were educated the importance of lag screw positioning at the same hospital.

Patients admitted at the same hospital for extra-capsular femoral fracture fixation were identified via the trauma co-ordinator. Peri-operative digital image intensifier radiographs were obtained and scanned (AP and lateral).

Radiographs were scanned using Vidar digital X-ray scanner (Vidar Systems, Herndon, USA) and Imagika (View Tec, Zurich, Switzerland). Each digital image was calibrated before measurement, to calibrate for magnification.

The tip of the lag screw to the apex of the femoral head was measured in each image by two independent observers and the results were combined to derive a mean value. The measurements of the tip of the lag screw of the implant to the apex of the femoral head in both the AP and lateral view allowed the calculation of the "tip apex distance" (TAD) for each fracture fixed.

This study was an audit of the existing clinical practice at the time, demonstrating improvements in performance after education of the importance of TAD. As this is not a research project, we did not alter patient's care or management but simply evaluated current practice and educated colleagues by using measurements taken from postoperative radiographs. Ethics committee approval was, therefore, not required for this purpose as per the institutional guidelines.

The authors confirm that this study conforms to the Declaration of Helsinki.

\section{Results}

Data were collected using statistical software (SPSS statistical software version 12.01) into two statistical groups (retrospective data and prospective data).

Box plots and histograms were produced from the data and were deemed parametric, hence $t$ test analysis was conducted on the data.

The patients whose radiographs were analysed retrospectively had an average age of 84 , and patients analysis prospectively had an average age of 79 . The 75 patients analysed retrospectively consisted to 57 females and 18 males. The 83 patients analysed prospectively consisted to 57 females and 26 males.

Average TAD in radiographs measured retrospectively was $22.6 \mathrm{~mm}$ (SD $6.2 \mathrm{~mm}$; range 9.8-37.4 mm) compared with $9.7 \mathrm{~mm}$ (SD $3.2 \mathrm{~mm}$; range $4.1-19.5 \mathrm{~mm}$ ) in radiographs analysed prospectively (Table 2). Student $t$ test analysis determined this difference to be statistically significant $(P \leq 0.001)$. The power of this study was $97 \%$.

\section{Discussion}

The concept of TAD was introduced by Baumgaertner and is associated with cutting out of the lag screw from the femoral head, which is the most common cause of failure of fixation in an extracapsular fracture neck of femur $[1,2]$.

Table 2 Summary of TAD values between retrospective radiographs and prospective radiographs (SD in brackets)

\begin{tabular}{lll}
\hline & $\begin{array}{l}\text { Retrospective } \\
\text { radiographs }\end{array}$ & $\begin{array}{l}\text { Prospective } \\
\text { radiographs }\end{array}$ \\
\hline $\begin{array}{l}\text { Number of radiographs } \\
\text { analysed }\end{array}$ & 75 & 83 \\
\begin{tabular}{l} 
Mean TAD \\
\hline
\end{tabular} & $22.6(7.0)$ & $9.7(3.2)$ \\
\hline
\end{tabular}


Parker and Pervez have studied the optimum positioning of the lag screw in femoral fracture fixation, and deduced that TAD should be less than 25 and $20 \mathrm{~mm}$ in each of their studies (Table 1) [3].

This study involved comparing 75 radiographs analysed retrospectively with 83 radiographs analysed prospectively, with surgical training introducing the awareness of TAD prior to prospective measurements.

Those surgeons introduced to the concept of "tip apex distance" fixed extracapsular femoral fractures more accurately than those surgeons not introduced to the concept of "tip apex distance". This was found to be statistically significant $(P<0.001)$. A larger proportion of radiographs complied with advice from Baumgaertner that "tip apex distance" should be less $25 \mathrm{~mm}$ when compared with prospective radiographs.

This study demonstrates that introducing the concept of "tip apex distance" to surgeons, will improve the accuracy of lag screw placement during fixation of an extracapsular fracture. The improvements in lag screw placement will undoubted reduce the risk of cut-out of the implant postsurgery.

The methods of measuring TAD in the radiographs were deemed valid from other studies conducted at the department. Additionally, errors in recording have been highlighted due to differences in rotation of the femoral head in the radiographs [4]. We believe that in this study these errors are randomised between the retrospective and prospective data analysis, and hence do not contribute to errors in data analysis.

In conclusion, the null hypothesis can be rejected as this study has proven that the introduction of the concept of "tip apex distance" will affect the accuracy of lag screw placement. This correlates with the findings of Baumgaertner, who also assessed the importance of introducing lag screw placement to surgeons [2].

Conflict of interest statement The authors declare that they have no conflict of interest related to the publication of this manuscript.

\section{References}

1. Parker MJ (1992) Cutting-out of the dynamic hip screw related to its position. J Bone Joint Surg Br 74(4):625

2. Baumgaertner MR, Curtin SL et al (1995) The value of the tipapex distance in predicting failure of fixation of peritrochanteric fractures of the hip. J Bone Joint Surg-Am Vol 77(7):1058-1064 (see comment)

3. Parker M, Handoll H (2004) Gamma and other cephalocondylic intramedullary nails versus extramedullary implants for extracapsular hip fractures. Cochrane Database Syst Rev (1):CD000093

4. Kumar AJ, Parmar VN, Kolpattil S, Humad S, Williams SC, Harper WM (2007) Significance of hip rotation on measurement of 'Tip Apex Distance' during fixation of extracapsular proximal femoral fractures. Injury 38(7):792-796 